\title{
Characteristics of Belgian "life-ending acts without explicit patient request": a large-scale death certificate survey revisited
}

\author{
Kenneth Chambaere PhD, Jan L. Bernheim MD PhD, James Downar MDCM MHSc, Luc Deliens PhD
}

Abstract

Background: "Life-ending acts without explicit patient request," as identified in robust international studies, are central in current debates on physician-assisted dying. Despite their contentiousness, little attention has been paid to their actual characteristics and to what extent they truly represent nonvoluntary termination of life.

Methods: We analyzed the 66 cases of life-ending acts without explicit patient request identified in a large-scale survey of physicians certifying a representative sample of deaths $(n=6927)$ in Flanders, Belgium, in 2007 . The characteristics we studied included physicians' labelling of the act, treatment course and doses used, and patient involvement in the decision.

Results: In most cases (87.9\%), physicians labelled their acts in terms of symptom treatment rather than in terms of ending life. By comparing drug combinations and doses of opioids used, we found that the life-ending acts were similar to intensified pain and symptom treatment and were distinct from euthanasia. In 45 cases, there was at least 1 characteristic inconsistent with the common understanding of the practice: either patients had previously expressed a wish for ending life (16/66, 24.4\%), physicians reported that the administered doses had not been higher than necessary to relieve suffering $(22 / 66,33.3 \%)$, or both $(7 / 66,10.6 \%)$.

Interpretation: Most of the cases we studied did not fit the label of "nonvoluntary life-ending" for at least 1 of the following reasons: the drugs were administered with a focus on symptom control; a hastened death was highly unlikely; or the act was taken in accordance with the patient's previously expressed wishes. Thus, we recommend a more nuanced view of life-ending acts without explicit patient request in the debate on physician-assisted dying.

$\mathrm{F}$ ew issues in medical academia are as ethically pertinent and emotionally charged as assisted dying and its legal regulation. Observers worldwide are closely scrutinizing developments in Belgium and the Netherlands, where euthanasia (defined in legal and scientific terms as lethal drug administration at the explicit request of the patient) and assisted suicide have been regulated since 2002 and where, among other research, repeated population-based surveys monitor developments and inform the ongoing debate..$^{1-7}$ These surveys report prevalence and characteristics of end-of-life practices. These practices include a wide array of acts potentially influencing time of death in addition to euthanasia, such as the administration of drugs with the explicit intention to hasten death without the patient's explicit request, or "life-ending acts without explicit patient request."

These acts are often understood as physician-initiated nonvoluntary or involuntary termination of life. They feature prominently in debates over assisted dying and are regarded as an indicator of the ineffectiveness of safeguards for legal euthanasia and a slippery slope to undesirable practices. ${ }^{8,9}$ Studies have found that although the legalization of assisted death was followed by a reduction in the occurrence of these acts, it did not put an end to the practice. ${ }^{6,7}$ In addition, although these acts occur in nonpermissive countries,,$^{2,10-12}$ their rate in Belgium remains higher than elsewhere. ${ }^{2,4-6,10-12}$

Little attention has been paid to the characteristics of cases in which life has been ended without explicit patient request. A previous publication comparing cases of euthanasia and lifeending acts without explicit patient request in Belgium identified important differences in terms of decision-making and drugs used. Life-ending acts without explicit patient request

Competing interests: James Downar is cochair of the Physician's Advisory Committee for Dying with DIgnity, a nonprofit organization that advocates for the legalization of assisted death.

This article has been peer reviewed.

Correspondence to: Kenneth Chambaere, kenneth.chambaere@vub.ac.be CMAJ Open 2014. DOI:10.9778/cmajo.20140034 
predominantly involved the use of opioids, which are rarely used in euthanasia, and life-shortening was often estimated at less than 24 hours by physicians. ${ }^{5}$ These findings raised questions about whether these acts are truly equivalent to nonvoluntary termination of life. With several countries including Canada, Australia and the United Kingdom bringing the debate over assisted death to legislative levels, in-depth analysis of the practices surrounding these acts is of immediate relevance.

Our aim is to revisit in detail the cases in which these acts were identified in a representative mail survey of physicians certifying 6927 deaths in Belgium in $2007^{13}$ to determine to what extent these cases represent nonvoluntary termination of life. We examined the relevant survey data on the terms physicians used to denote their acts, the characteristics of drugs and doses used, and the patients' involvement in decision-making.

\section{Methods}

\section{Study design}

In 2007, we conducted a large-scale death certificate survey in Flanders, the semiautonomous northern half of Belgium with a population of about 6 million people and 55000 deaths per year. Between June and November, we drew a sample of 6927 deaths from the Flemish Agency for Care and Health, with disproportionate stratification into 4 strata based on cause of death and the corresponding likelihood of an end-of-life decision potentially hastening death. This stratification was used to capture more cases with end-of-life decisions for statistical power: we sampled $100 \%$ of deaths with euthanasia designated as cause of death on the death certificate (in free text or classified as Z41 using the International Statistical Classification of Diseases and Related Health Problems, 10th revision), $50 \%$ of malignancy deaths (ICD-10 code C), $25 \%$ of deaths classified with ICD-10 codes E,F,G,J,K or N, and $12.5 \%$ of deaths with any other cause of death.

We sent a 5-page questionnaire on end-of-life decisions and practices to the certifying physicians, along with a letter explaining the study, with a maximum of 3 reminders and a nonresponse questionnaire in case no response was received. Response was regarded as implicit consent to participate. The study protocol and rigorous mailing procedure involving a lawyer as intermediary between physicians and researchers guaranteed total anonymity for participating physicians and their patients and was approved by the Ethical Review Boards of the University Hospitals of the Vrije Universiteit Brussels and Ghent University, and endorsed by the Belgian Medical Disciplinary Board and the Belgian Federal Privacy Commission. Information from the death certificates on sex, age, place of death and cause of death was encoded by the Agency for Care and Health to preclude any identification of patients or physicians. The survey methods have been detailed in a protocol paper. ${ }^{13}$

\section{Questionnaire}

The questionnaire was extensively validated in previous studies in Belgium and other European countries, ${ }^{1-7}$ and again for the present study. We identified cases of "life-ending acts without explicit request" as in previous studies: ${ }^{17,11,12}$ an affirmative response to the question "Was the death the consequence of the use of drugs prescribed, supplied or administered by you or another physician with the explicit intention of hastening the end of life or of enabling the patient to end their own life?" and a negative response to the question "Was the decision made after an explicit request by the patient?" Additional questions (Appendix 1, www.cmajopen.ca/content/2/4/E262/suppl /DC1) dealt with the drugs and doses used for the act, characteristics of treatment in the patient's final days, whether the patient had at some point expressed a wish for life to be ended (implicitly or explicitly, but not as a formal euthanasia request), and the term that best described the act according to the physicians themselves (we presented a list of predetermined options with one open category of "other").

\section{Data collection}

We performed a detailed case-by-case review of physicianreported characteristics of drug treatment and patient involvement. To determine whether the opioid doses were higher than necessary to relieve symptoms, we used the judgment of the physician completing the survey. We defined low-dose benzodiazepines as any dose of lorazepam less than or equal to $2.5 \mathrm{mg}$, diazepam less than or equal to $20 \mathrm{mg}$ (or no dose indicated) or midazolam less than or equal to $2 \mathrm{mg}$. We defined high-dose benzodiazepines as more than $2.5 \mathrm{mg}$ lorazepam or more than $2 \mathrm{mg}$ (or no dose indicated) midazolam. We classified high-dose benzodiazepines, propofol and barbiturates as "strong sedatives." We determined that a patient did not have a life-ending act if he or she had received opioid doses no higher than necessary for symptom control and only low-dose benzodiazepines. We determined that a patient had a life-ending act performed if he or she received opioid doses higher than necessary for symptom control, with or without strong sedatives. For unknown drug doses, we ascribed a lethal potential to short-acting midazolam, but not to diazepam because of its long and delayed action.

\section{Statistical analysis}

We chose not to weight cases for the disproportionate stratification and nonresponse, because our aim was to describe the raw cases captured in the survey and not to present them as representative for all deaths via life-ending act without explicit patient request, and a comparison of analyses using unweighted and weighted data showed no significant differences (Appendix 2, www.cmajopen.ca/content/2/4/E262 /suppl/DC1). We used $\chi^{2}$ to determine the significance $(p<$ $0.05)$ of differences between end-of-life practices. We used SPSS 22.0 to perform all analyses.

\section{Results}

We received responses for 3623 of the 6927 deaths sampled, for a response rate of $58.4 \%$. From these responses, we identified 66 cases of life-ending acts without explicit patient request (Table 1). The nonresponse survey identified 725 cases for which a response was not possible (physician was unable to 
identify the patient or unable to retrieve the patient file; treating physician could not be reached).

We identified the terms best describing the acts according to the reporting physicians. The options "palliative sedation" (68.2\%) and "symptom treatment" (19.7\%) were selected most often, whereas "compassionate life-ending" was chosen in $6.1 \%$ of cases (Table 2). "Euthanasia" was never selected.

We compared cases of life-ending acts without explicit patient request with cases of euthanasia and the intensified alleviation of pain or symptoms (taking into account possible life-shortening) with respect to the drugs and opioid doses administered in the patient's final 24 hours (Table 3). Data for doses was missing for many cases; however, we did find significant differences between life-ending acts without explicit patient request and euthanasia in terms of drugs used. Drugs other than opioids were used more often in euthanasia than in life-ending acts without explicit patient request $(59.7 \% \mathrm{v}$. $6.1 \%, p<0.001$; Table 3). When opioids were used in euthanasia, the dose was generally higher than that used in the lifeending acts without explicit patient request $(p=0.04$; Table 3$)$. We found no significant differences between life-ending acts without explicit patient request and intensified alleviation of pain and other symptoms in terms of the combinations of drugs used $(p=0.2)$ or doses $(p=0.9)$ (Table 3$)$. In both practices, opioids were used in more than $90 \%$ of cases (Table 3 ).

Table 1: Characteristics of physicians and patients involved in life-ending acts without explicit patient request

\begin{tabular}{|lc|}
\hline Characteristic & $\begin{array}{c}\text { No. }(\%) \\
n=66\end{array}$ \\
\hline Physician specialty & $33(50.0)$ \\
\hline Family physician & $33(50.0)$ \\
\hline Specialist & \\
\hline Patient age, yr & $10(15.2)$ \\
\hline $1-64$ & $28(42.4)$ \\
\hline $65-79$ & $28(42.4)$ \\
\hline$\geq 80$ & \\
\hline Patient sex & $34(51.5)$ \\
\hline Male & $32(48.5)$ \\
\hline Female & \\
\hline Patient cause of death (as listed on death certificate) & $41(62.1)$ \\
\hline Cancer & $10(15.2)$ \\
\hline $\begin{array}{l}\text { Cardiovascular disease } \\
\text { (including cerebrovascular accident) }\end{array}$ & $11(16.7)$ \\
\hline Respiratory disease & $5(7.6)$ \\
\hline Neurological disease & $3(4.5)$ \\
\hline Other disease & $7(10.6)$ \\
\hline Patient place of death & $22(33.3)$ \\
\hline Home & $32(48.5)$ \\
\hline Hospital & \\
\hline Nursing home & \\
\hline Other & \\
\hline & \\
\hline
\end{tabular}

Of the 66 cases we identified, the doses of opioids administered in 29 cases $(43.9 \%)$ were reported by the attending physician to be no higher than necessary to relieve symptoms, with or without low-dose benzodiazepines (Table 4). In another 15 cases $(22.7 \%)$, opioids were administered in doses reportedly higher than necessary to relieve symptoms (Table 4). In 20 cases $(30.3 \%)$, the patients were given strong sedatives (Table 4). In 23 cases $(34.8 \%)$, patients had explicitly or implicitly expressed a wish for life-ending at some point (Table 4). In 45 cases $(68.2 \%)$, the act had at least 1 characteristic that is inconsistent with the common understanding of the practice of lifeending acts without explicit patient request: either physicians administered doses that were no higher than necessary for symptom control ( $n=22$ patients among those who had not expressed a wish to end life), patients had expressed a wish to end their life ( $n=16$ patients among those who received drugs not normally used as part of mainstream palliative care) or both $(n=7)$ (Table 4).

\section{Interpretation}

In most cases, physicians reporting life-ending acts without explicit patient request did not label their acts in terms of lifeending, but rather in terms of symptom treatment. A comparison of drug combinations and opioid doses used showed these acts to be similar to intensified pain and symptom treatment and significantly distinct from euthanasia. Finally, in $68.1 \%$ of cases, the physician did not perform a life-ending act without request, either because they did not administer medication in a dose that was higher than necessary for symptom control, or because the patient had expressed a wish to end their life, or both.

This study elaborates on the results of previous studies $^{5,18,19}$ that have shown that the medications provided in life-ending acts without explicit patient request are significantly different from those provided in euthanasia and similar to those provided in standard palliative care. In addition, the terminology used by physicians suggests that their focus was not on hastening death, and other studies have presented similar results. ${ }^{18-21}$ Finally, the use of stable or slowly increasing doses of opioids no higher than necessary for symptom con-

Table 2: Term used for life-ending acts without explicit patient consent by physicians

\begin{tabular}{|c|c|}
\hline Term & $\begin{array}{c}\text { No. }(\%) \\
n=66\end{array}$ \\
\hline Symptom treatment & $13(19.7)$ \\
\hline Palliative sedation & $45(68.2)$ \\
\hline Compassionate life-ending & $4 \quad(6.1)$ \\
\hline Euthanasia & $0 \quad(0.0)$ \\
\hline Other & $4 \quad(6.1)$ \\
\hline
\end{tabular}


trol makes it unlikely that death was actually hastened in many cases. Several previous studies have reported that even high-dose opioids are most often ineffective at hastening death, especially when doses are proportionate to the severity of a patient's symptoms. ${ }^{14,22-29}$

How can the contradiction between intention and act be explained? Many physicians continue to believe that opioids hasten death at even moderate doses and feel that adequate symptom treatment would concomitantly hasten the patient's death (if only by a small amount of time). ${ }^{5,30}$ Furthermore, a physicians' interpretation of "explicit intention" may be subjective or semantic — they may have meant "partial intention" or hope that the patient would pass on quickly and comfortably. Previous studies have already put forward this idea and the idea that some medical cultures may be more inclined to admitting so than others. ${ }^{31,32}$

Although the perception of these acts as the nonvoluntary termination of life is mitigated by our results, some ethical ambiguities remain inherent to the practice. Although the chosen treatment course often entailed no ill effects (i.e., comfort was in all likelihood achieved without hastening death, which is standard practice and preferable to forgoing effective treatment) and patients dying in discomfort, an explicit intent to hasten death in the absence of the patient's request is in itself objectionable, regardless of the outcome. In addition, amid active debate on the proper balance between respecting autonomy and paternalism in medicine, ${ }^{33}$ whether an implicit or explicit wish to end life, supposing it is regarded as a sufficient exertion of autonomy, can be acted upon is not straightforward. Such a wish cannot be ascribed the same legal weight as a formal request for euthanasia, but some physicians may see it as an important indication, in the absence of others, of the patient's preferences.

\section{Strengths and limitations}

We used robust source data obtained with rigorous methods that guaranteed anonymity and produced a reasonable response rate despite the medicolegal sensitivity of the subject. ${ }^{6,13}$ However, we cannot exclude some degree of nonresponse bias. Desirability biases in the source data are possible; despite strict anonymity, some physicians may not have reported life-ending acts without explicit patient request in the survey. Only the physicians' perspectives were studied. In addition, surveys are inevitably reductionist, and cannot fully capture the complexity and diversity of clinical cases and doctor-patient interactions at the end of life. Providing an options list for the term that best described physicians' acts may have introduced bias, though there was the possibility of a free text answer. Finally, we cannot exclude the possibility of poor recall in physicians' reporting, particularly of drugs and doses where missing data may have biased the results.

\begin{tabular}{|c|c|c|c|}
\hline Drugs and doses used $\dagger$ & $\begin{array}{l}\text { Intensified alleviation } \\
\text { of pain and other } \\
\text { symptoms, } \\
\text { No. (\%) } \\
n=1249\end{array}$ & $\begin{array}{l}\text { Life-ending act } \\
\text { without explicit } \\
\text { patient request, } \\
\text { No. (\%) } \\
n=66\end{array}$ & $\begin{array}{l}\text { Euthanasia or } \\
\text { assisted suicide, } \\
\text { No. (\%) } \\
n=142\end{array}$ \\
\hline Drugs & $n=1199$ & $n=65$ & $n=139$ \\
\hline Opioids & $1139(95.0)$ & $61(93.8)$ & $56(40.3)$ \\
\hline As the only drug & $703(58.6)$ & $29(44.6)$ & $22(15.8)$ \\
\hline With benzodiazepines & $284(23.7)$ & $17(26.2)$ & $20(14.4)$ \\
\hline $\begin{array}{l}\text { With drugs other than } \\
\text { benzodiazepines }\end{array}$ & 78 (6.5) & $8(12.3)$ & $3(2.1)$ \\
\hline With benzodiazepines and other drugs & $74 \quad(6.2)$ & $7(10.8)$ & $11(7.9)$ \\
\hline No opioids & $60(5.0)$ & $4(6.1)$ & $83(59.7)$ \\
\hline$\chi^{2} p$ value & 0.2 & & $<0.001$ \\
\hline $\begin{array}{l}\text { Reported OME opioid doses used in } \\
\text { last } 24 \mathrm{h \ddagger}, \mathrm{mg}\end{array}$ & $n=821$ & $n=37$ & $n=44$ \\
\hline $1-119$ & $307(37.4)$ & $14(37.8)$ & $6(13.6)$ \\
\hline 120-239 & $267(32.5)$ & $10(27.0)$ & $10(22.7)$ \\
\hline 240-479 & $179(21.8)$ & $10(27.0)$ & $21(47.7)$ \\
\hline$\geq 480$ & 68 (8.3) & $3(8.1)$ & 7 (15.9) \\
\hline$\chi^{2} p$ value & 0.9 & & 0.04 \\
\hline \multicolumn{4}{|c|}{$\begin{array}{l}\text { Note: OME = oral morphine equivalent. } \\
\text { *Administration of drugs for the treatment and management of pain or other symptoms, taking into account a potential life-shortening effect. } \\
\text { †Cases with missing values were excluded from the analysis. } \\
\text { †Conversion rates were obtained from handbooks and review publications with equianalgesic tables. }{ }^{14-17}\end{array}$} \\
\hline
\end{tabular}




\section{Conclusions and recommendations for research, practice and policy}

Our analysis challenges the perception that life-ending acts without explicit patient request are equivalent to nonvoluntary termination of life. Many of the acts identified in our survey were either in accordance with a patient's wish to die (albeit not in the form of a legally prescribed euthanasia request) or without actual life-terminating effect. A more nuanced view of these acts is warranted in the debate over assisted death.

Our findings further suggest that physicians might benefit from education on standards of decision-making and the effects of high-dose opioids in terms of life-shortening potential. Such knowledge would contribute to achieving both ethically coherent and clinically effective end-of-life practice.

To better understand the wishes of patients regarding assisted death and the responses of physicians to these wishes, we propose complementary research as part of prospective studies on advance care planning. To explore the considerations and motivations of all stakeholders, and to better distinguish life-ending acts without explicit patient request from uncontroversial practices, in-depth interviews with physicians, nurses, patients and relatives are worthwhile. ${ }^{18}$ Crossnational vignette studies on end-of-life practices should help establish whether clinical situations and end-of-life treatments are interpreted or labelled differently across countries and medical cultures.

\section{References}

1. Deliens L, Mortier F, Bilsen J, et al. End-of-life decisions in medical practice in Flanders, Belgium: a nationwide survey. Lancet 2000;356:1806-11.

2. van der Heide A, Deliens L, Faisst K, et al. End-of-life decision-making in six European countries: descriptive study. Lancet 2003;362:345-50.

3. van der Heide A, Onwuteaka-Philipsen BD, Rurup ML, et al. End-of-life practices in the Netherlands under the euthanasia act. $N$ Engl $7 \mathrm{Med}$ 2007;356:1957-65.

4. Bilsen J, Cohen J, Chambaere K, et al. Medical end-of-life practices under the euthanasia law in Belgium: a nationwide post-mortem survey. $N$ Engl $f$ Med 2009;361:1119-21.

5. Chambaere K, Bilsen J, Cohen J, et al. Physician assisted deaths under the euthanasia law in Belgium: a population-based survey. CMAJ 2010;182. 895-901.

6. Chambaere K, Bilsen J, Cohen J, et al. Trends in medical end-of-life decision making in Flanders, Belgium 1998-2001-2007. Med Decis Making 2011; 31:500-10.

7. Onwuteaka-Philipsen BD, Brinkman-Stoppelenburg A, Penning C, et al. Trends in end-of-life practices before and after the enactment of the euthanasia law in the Netherlands from 1990 to 2010: a repeated cross-sectional survey. Lancet 2012;380:908-15.

8. Pereira J. Legalizing euthanasia or assisted suicide: the illusion of safeguards and controls. Curr Oncol 2011;18:e38-45.

9. Lewis P. The empirical slippery slope from voluntary to non-voluntary euthanasia. 7 Law Med Ethics 2007;35:197-210.

10. Seale C. Hastening death in end-of-life care: a survey of doctors. Soc Sci Med 2009;69:1659-66.

11. Kuhse H, Singer P, Baume P, et al. End-of-life decisions in Australian medical

Table 4: Classification of life-ending acts without explicit patient request according to drugs and doses used and expressed wish for life ending*

\begin{tabular}{|c|c|c|c|c|c|c|}
\hline \multirow[b]{2}{*}{ Drug(s) used } & \multirow[b]{2}{*}{ Administration schedule } & \multicolumn{2}{|c|}{ Expressed wish to end life } & \multicolumn{2}{|c|}{$\begin{array}{l}\text { No expressed wish } \\
\text { to end life }\end{array}$} & \multirow[b]{2}{*}{ Tota } \\
\hline & & Explicit & Implicit & $\begin{array}{c}\text { Patient } \\
\text { incapable }\end{array}$ & $\begin{array}{l}\text { Patient } \\
\text { capable }\end{array}$ & \\
\hline \multirow{3}{*}{$\begin{array}{l}\text { Opioid dose no } \\
\text { higher than } \\
\text { necessary for } \\
\text { symptom } \\
\text { control, with or } \\
\text { without low-dose } \\
\text { benzodiazepines }\end{array}$} & Stable dose over final $3 \mathrm{~d}$ & 1 & 1 & 7 & 2 & 11 \\
\hline & Gradual increase in opioids over final $3 \mathrm{~d}$ & 1 & 2 & 8 & 2 & 13 \\
\hline & Strong increase in opioids on final day & 2 & & 3 & & 5 \\
\hline \multirow{3}{*}{$\begin{array}{l}\text { Opioid doses or } \\
\text { sedatives not } \\
\text { normally used } \\
\text { as part of } \\
\text { mainstream } \\
\text { palliative care }\end{array}$} & $\begin{array}{l}\text { Opioid doses exceeding symptom } \\
\text { requirements, but either stable or } \\
\text { gradually increasing, with or without } \\
\text { low-dose benzodiazepines }\end{array}$ & & & 3 & 1 & 4 \\
\hline & $\begin{array}{l}\text { Opioid doses exceeding symptom } \\
\text { requirements and strongly rising on last } \\
\text { day, with or without low-dose } \\
\text { benzodiazepines }\end{array}$ & 3 & 2 & 6 & & 11 \\
\hline & $\begin{array}{l}\text { Strong sedatives (barbiturates, propofol } \\
\text { or high-dose benzodiazepines) }\end{array}$ & 3 & 7 & 9 & 1 & 20 \\
\hline $\begin{array}{l}\text { Unspecified } \\
\text { doses of opioids, } \\
\text { benzodiazepines } \\
\text { or both }\end{array}$ & & & 1 & 1 & & 2 \\
\hline Total & & 10 & 13 & 37 & 6 & 66 \\
\hline
\end{tabular}


practice. Med 7 Aust 1997;166:191-6.

12. Mitchell K, Owens RG. National survey of medical decisions at end of life made by New Zealand general practitioners. BMF 2003;327:202-3.

13. Chambaere K, Bilsen J, Cohen J, et al. A post-mortem survey on end-of-life decisions using a representative sample of death certificates in Flanders, Belgium: research protocol. BMC Public Health 2008;8:299.

14. Hanks GWC, Cherny NI. Opioid analgesic therapy. In: Doyle D, Hanks GWC, MacDonald N, editors. The Oxford textbook of palliative medicine. 2nd ed. Oxford (UK): Oxford University Press; 1998: 331-55.

15. Knotkova H, Fine PG, Portenoy RK. Opioid rotation: the science and the limitations of the equianalgesic dose table. 7 Pain Symptom Manage 2009; 38:426-39.

16. de Graeff A, Hesselman GM, Krol RJA, et al., editors. Palliative care: guidelines for practice [Dutch]. Utrecht: VIKC; 2006.

17. Pereira J, Lawlor P, Vigano A, et al. Equianalgesic dose ratios for opioids: a critical review and proposals for long-term dosing. 7 Pain Symptom Manage 2001;22:672-87.

18. Meeussen K, Van den Block L, Bossuyt N, et al. Physician reports of medication use with explicit intention of hastening the end of life in the absence of explicit patient request in general practice in Belgium. BMC Public Health 2010;10:186.

19. Rietjens JA, Bilsen J, Fischer S, et al. Using drugs to end life without an explicit request of the patient. Death Stud 2007;31:205-21.

20. Deliens L, Ganzini L, Vander Stichele R. The use of drugs to hasten death. Pharmacoepidemiol Drug Saf 2004;13:113-5.

21. Pijnenborg L, van der Maas PJ, van Delden JJ, et al. Life-terminating acts without explicit request of patient. Lancet 1993;341:1196-9.

22. Sykes $\mathrm{N}$, Thorns A. Sedative use in the last week of life and the implications for end-of-life decision making. Arch Intern Med 2003;163:341-4.

23. Sykes N, Thorns A. The use of opioids and sedatives at the end of life. Lancet Oncol 2003;4:312-8.

24. Thorns A, Sykes N. Opioid use in last week of life and implications for endof-life decision-making. Lancet 2000;356:398-9.

25. Bercovitch M, Waller A, Adunsky A. High dose morphine use in the hospice setting. A database survey of patient characteristics and effect on life expectancy. Cancer 1999;86:871-7.

26. Portenoy RK, Sibirceva U, Smout R, et al. Opioid use and survival at the end of life: a survey of a hospice population. 7 Pain Symptom Manage 2006;32: 532-40.

27. Morita T, Tsunoda J, Inoue S, et al. Effects of high dose opioids and sedatives on survival in terminally ill cancer patients. 7 Pain Symptom Manage 2001; 21:282-9.

28. Hallenbeck J. Pathophysiologies of dyspnea explained: Why might opioids relieve dyspnea and not hasten death? $\mathcal{F}$ Palliat Med 2012;15:848-53.

29. Fineberg IC, Wenger NS, Brown-Saltzman K. Unrestricted opiate administration for pain and suffering at the end of life: knowledge and attitudes as barriers to care. 7 Palliat Med 2006;9:873-83.
30. Vander Stichele RH, Bilsen JJ, Bernheim JL, et al. Drugs used for euthanasia in Flanders, Belgium. Pharmacoepidemiol Drug Saf 2004;13:89-95.

31. Draper H, Ives J, Pall H, et al. Reporting end-of-life practice: Can we trust doctors to be honest? Palliat Med 2009;23:673-4.

32. Cohen L, Ganzini L, Mitchell C, et al. Accusations of murder and euthanasia in end-of-life care. 7 Palliat Med 2005;8:1096-104.

33. Roeland E, Cain J, Onderdonk C, et al. When open-ended questions don't work: the role of palliative paternalism in difficult medical decisions. 7 Palliat Med 2014;17:415-20.

Affiliations: End-of-Life Care Research Group (Chambaere, Bernheim, Deliens), Vrije Universiteit Brussel (VUB) \& Ghent University, Brussels, Belgium; Department of Medicine (Downar), University Health Network, Toronto, Ont.; University of Toronto (Downar), Toronto, Ont.; Department of Medical Oncology (Deliens), University Hospital Ghent, Ghent, Belgium.

Contributors: Jan Bernheim, Kenneth Chambaere and Luc Deliens conceived and designed the study. Kenneth Chambaere and Luc Deliens acquired the data. Kenneth Chambaere, Jan Bernheim and James Downar analyzed the data. All of the authors interpreted the data. Kenneth Chambaere and Jan Bernheim drafted the article. All of the authors made critical revisions for intellectual content, approved the final version submitted for publication, and agreed to be accountable for all aspects of the work in ensuring that questions related to its accuracy or integrity are appropriately investigated and resolved.

Funding: This study was funded by the Agency for the Promotion of Innovation by Science and Technology — Flanders (IWT Vlaanderen grant no. IWT050158). The funding agreement ensured the authors' independence in designing the study, interpreting the data, and writing and publishing the report. Kenneth Chambaere is a Postdoctoral Fellow of the Research Foundation - Flanders (FWO).

Acknowledgments: The authors thank the Flemish Agency for Care and Health and Wim De Brock for their participation in the organization of data collection; Geert Pousset for his part in collecting the data; the Belgian Medical Disciplinary Board for recommending the study; and the anonymous physicians who participated in the survey.

Supplemental information: For reviewer comments and the original submission of this manuscript, please see www.cmajopen.ca/content/2/4/ E262/suppl/DC1 